\title{
Paraneoplastic AQP4-IgG-Seropositive Neuromyelitis Optica Spectrum Disorder Associated With Teratoma
}

\author{
A Case Report and Literature Review
}

\author{
Ryotaro Ikeguchi, MD, PhD, Yuko Shimizu, MD, PhD, Ayato Shimomura, MD, Miki Suzuki, MD, PhD, \\ Kanoko Shimoji, MD, Takashi Motohashi, MD, Tomoko Yamamoto, MD, PhD, Noriyuki Shibata, MD, PhD, and \\ Kazuo Kitagawa, MD, PhD
}

Neurol Neuroimmunol Neuroinflamm 2021;8:e1045. doi:10.1212/NXI.0000000000001045

\section{Abstract}

\section{Objectives}

To assess a case of paraneoplastic aquaporin-4 (AQP4)-immunoglobulin G (IgG)-seropositive neuromyelitis optica spectrum disorder (NMOSD) associated with teratoma and determine whether it is a paraneoplastic neurologic disorder.

\section{Methods}

A single case study and literature review of 5 cases.

\section{Results}

A 27-year-old woman presented with diplopia, facial nerve palsy, paraplegia, sensory dysfunction of lower limbs, dysuria, nausea, and vomiting. Spinal cord MRI detected an extensive longitudinal lesion in the spinal cord, and brain MRI detected abnormal lesions in the right cerebral peduncle and tegmentum of the pons. CSF analysis revealed positive oligoclonal IgG bands (OCBs). The patient tested positive for AQP4-IgG, confirming a diagnosis of NMOSD. An abdominal CT scan detected an ovarian tumor. After steroid therapy and tumor removal, the patient progressively improved, with only mild sensory dysfunction. Histopathologic analysis of the tumor revealed a teratoma and the presence of glial fibrillary acidic protein $(\mathrm{GFAP})^{+}$neural tissue with AQP4 immunoreactivity, accompanied by lymphocyte infiltration. Including the present case, there have been 6 reported cases of AQP4-IgG-seropositive NMOSD associated with ovarian teratoma (mean onset age, 32.7 years). Of these patients, 5 (83\%) presented with nausea and/or vomiting, positive OCB, and dorsal brainstem involvement. Pathologic analyses of the teratoma were available in 5 cases, including the present case, revealing neural tissue with AQP4 immunoreactivity and lymphocyte infiltration in all cases.

\section{Conclusions}

This study suggests that ovarian teratoma may trigger the development of AQP4IgG-seropositive NMOSD. Further studies are needed to elucidate the pathogenesis of teratoma-associated NMOSD.

\author{
Correspondence \\ Dr. Shimizu \\ shimizu.yuko@twmu.ac.jp
}




\section{Glossary}

AQP4 = aquaporin-4; IgG = immunoglobulin G; GFAP = glial fibrillary acidic protein; NMDAR = N-methyl-D-aspartate receptor; NMOSD = neuromyelitis optica spectrum disorder; $\mathbf{O C B}=$ oligoclonal IgG band; PND = paraneoplastic neurologic disorder.

Neuromyelitis optica spectrum disorder (NMOSD), an autoimmune disease of the CNS, is characterized by optic neuritis and myelitis. Aquaporin-4 antibodies (AQP4-immunoglobulin $\mathrm{G}[\mathrm{IgG}]$ ) have been detected in $80 \%$ of patients with NMOSD. Patients with malignancies can develop various neurologic disorders, including the paraneoplastic neurologic disorder (PND) induced by malignancy-associated autoimmune mechanisms. ${ }^{1}$ Recently, malignancies (such as breast and lung cancers) have been reported to trigger NMOSD through a paraneoplastic mechanism. ${ }^{2-4}$ In addition, there are several case reports of AQP4-IgG-seropositive NMOSD associated with teratomas. ${ }^{5-7}$ However, the relationship between teratoma and the development of NMOSD remains unclear.

This study describes a case of paraneoplastic NMOSD with a teratoma containing $\mathrm{GFAP}^{+}$neural tissue with AQP4 immunoreactivity and lymphocyte infiltration. Furthermore, we determine the clinical features of teratoma-associated NMOSD by reviewing 5 previously reported cases.

\section{Methods}

This is a single case study and literature review. Written informed consent was obtained from the patient. For the literature review, previously reported cases were systematically selected from PubMed using the key terms "teratoma," "NMOSD," and "paraneoplastic." Three case reports (5 cases) were identified and reviewed.

\section{Data Availability}

Anonymized data, for replicating the procedures, are available on reasonable request.

\section{Case Report}

A 27-year-old Chinese woman presented with chest and back pain a week after an upper respiratory tract infection. She was admitted to the hospital after developing diplopia, right facial nerve palsy, paraplegia, sensory dysfunction in the lower limbs, dysuria, nausea, and vomiting. MRI revealed an extensive longitudinal lesion in the spinal cord (C7-Th6), suggestive of myelitis (Figure 1A). Brain MRI showed fluid-attenuated inversion recovery hyperintense lesions in the right cerebral peduncle and tegmentum of the pons in contact with the fourth ventricle (Figure 1B). CSF analysis revealed 6 cells $/ \mu \mathrm{L}$ with mildly elevated protein $(47 \mathrm{mg} / \mathrm{dL})$ and positivity for oligoclonal $\mathrm{IgG}$ bands (OCBs). The patient tested positive for AQP4-IgG (>40 $\mathrm{U} / \mathrm{mL}$, assessed by ELISA) and negative for antithyroid, antinuclear, anti-DNA, anti-SSA/SSB, anti-myelin oligodendrocyte glycoprotein, GFAP $\alpha$-IgG, and anti-N-methyl-D-aspartate receptor (NMDAR) antibodies, confirming the diagnosis of
NMOSD. The condition of the patient improved markedly after 2 cycles of high-dose IV methylprednisolone therapy, followed by oral prednisolone and tacrolimus. Abdominal CT and MRI for liver dysfunction revealed a tumor in the left ovary, suggestive of a mature cystic teratoma (Figure 1C). Three months after onset, the ovarian tumor was removed. Pathologic investigations of the tumor revealed it to be a mature cystic teratoma (Figure 2, $\mathrm{A}$ and $\mathrm{B}$ ) that included the neural tissue exhibiting a $\mathrm{GFAP}^{+}$glial component with AQP4 immunoreactivity (Figure 2, C-E). Complement immunoreactivity on the vascular endothelial cells was observed (Figure 2F). This area showed mild inflammatory infiltrates, mainly composed of intensely stained $\mathrm{CD} 45 \mathrm{RO}^{+}$or $\mathrm{CD}^{+}$lymphocytes (Figure 2, G and $\mathrm{H}$ ). Conversely, only a few $\mathrm{CD} 20^{+} \mathrm{B}$ cells and $\mathrm{CD} 138^{+}$plasma cells were observed in the same region (Figure 2, I and J). Follow-ups conducted in the subsequent 16 months showed that the patient did not relapse, despite presenting with mild dysesthesia at the last neurologic examination.

\section{Review of the Literature and the Present Case}

Three reports presented 5 patients with AQP4IgG-seropositive NMOSD associated with teratoma who met the criteria of PND. ${ }^{5-7}$ Clinical details are shown in the Table . Including the present case, all 6 cases were females, with a mean onset age of 32.7 years (range, 15-50 years). In 1 case, anti-NMDAR encephalitis developed before NMOSD. ${ }^{6}$ Although the clinical symptoms varied, 5 of 6 cases (83\%) reported nausea and/or vomiting. All 6 patients presented with transverse myelitis, 2 with optic neuritis, and 5 with a dorsal brainstem lesion (1 with area postrema lesion). In the CSF analyses, 4 of 6 (67\%) cases showed mild to moderate pleocytosis, and 5 of $6(83 \%)$ cases showed OCB positivity. Histopathologic findings of teratoma were available for 5 of 6 cases (tumor resection was performed in all cases). All cases exhibited neural tissue in the tumor, with accompanying immune cell infiltration and a $\mathrm{GFAP}^{+}$glial component with AQP4 immunoreactivity. Complement immunoreactivity was observed only in the present case. AQP4-IgG was re-evaluated after removal of the teratoma, and negative conversion was observed in 3 of 5 cases (60\%). All patients showed a good response to immunotherapies, and only 1 patient who developed NMOSD after the onset of anti-NMDAR encephalitis relapsed after tumor removal. ${ }^{6}$ Although 2 cases reported residual visual deficits and dysesthesia, the other cases showed no sequelae.

\section{Discussion}

Generally, $3 \%-5 \%$ of NMOSDs are considered PND. ${ }^{2,3}$ Paraneoplastic NMOSD associated with cancer can be 

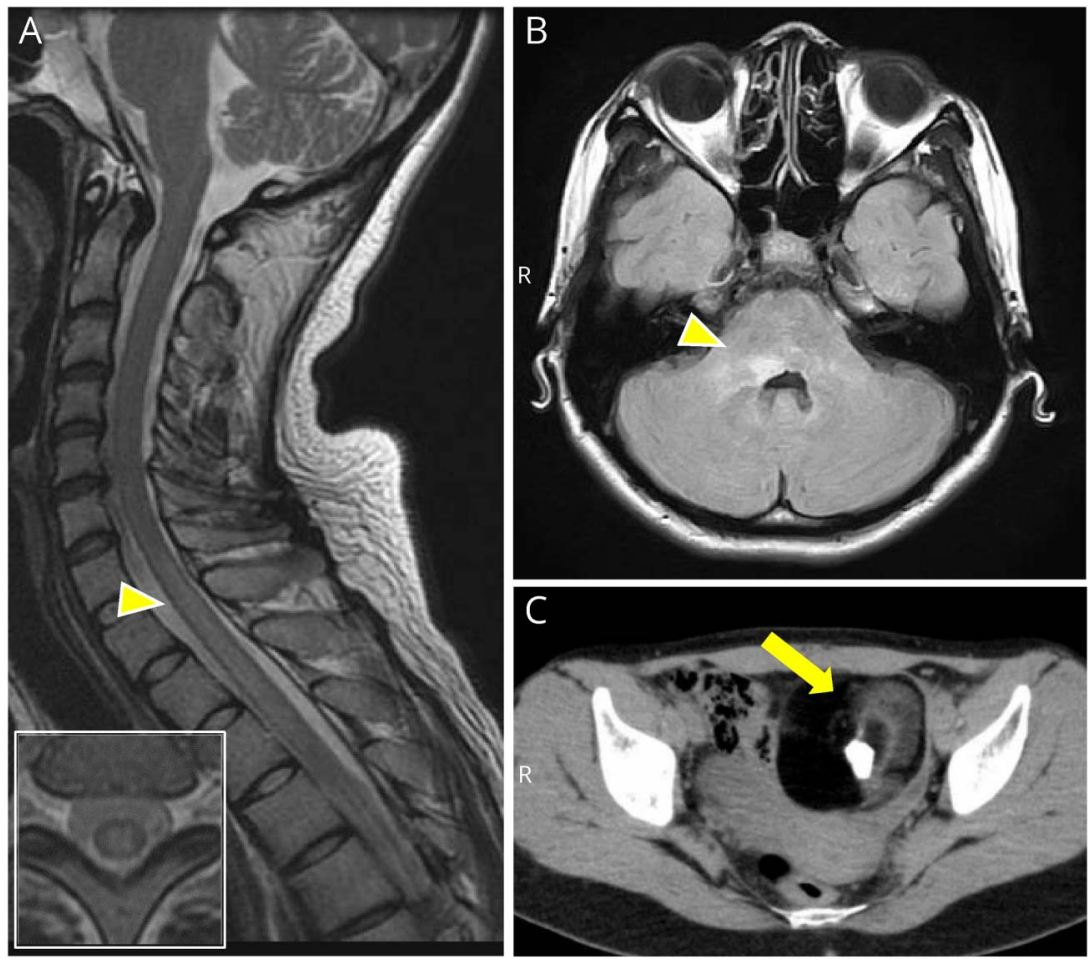

(A) T2-weighted images of the spinal cord show an extensive longitudinal hyperintense lesion in the spinal cord (C7-Th6, arrowhead). Inset in (A) is the axial image (Th1 level). (B) Axial fluid-attenuated inversion recovery (FLAIR) image of the brain shows a hyperintense lesion in the pontine tegmentum adjacent to the fourth ventricle (arrowhead). (C) Abdominal CT shows calcification and fat in the left ovarian tumor, which suggests ovarian teratoma (arrow).

mediated by intratumoral neural tissue expressing AQP4, triggering AQP4-IgG-related autoimmunity (intratumoral AQP4 is considered as an antigen). ${ }^{2,4}$ Among the discussed cases, we identified several common clinical features as explained below.

First, there was a high frequency of nausea and/or vomiting, consistent with a previous study of paraneoplastic NMOSD (nausea and vomiting were observed in $41.2 \%$ of paraneoplastic NMOSD and 6.6\% in nonparaneoplastic NMOSD). ${ }^{2}$ These are known symptoms of NMOSD (also called area postrema syndrome of the dorsal medulla). Although the involvement of the area postrema was described in only 1 case, a dorsal brainstem close to the area postrema lesion was observed in 5 of 6 cases. The area postrema is a vomiting center located in the caudal and dorsal brainstem, which lacks a blood-brain barrier and features the high expression of AQP4. ${ }^{8}$ These characteristics suggest that the area postrema is affected by antibody-related autoimmunity in NMOSD.

Second, we noted a high frequency of OCB positivity $(5 / 6)$ compared with that of nonparaneoplastic NMOSD, which is normally around $15 \% .{ }^{2,3}$ A high frequency of OCB positivity suggests significantly increased production of IgGs in the CNS. The OCB positivity rate is also low $(0 / 12)$ in the reported paraneoplastic NMOSD cases associated with tumors other than teratoma. ${ }^{2}$ Therefore, we speculate that intrathecal humoral immunity is strongly involved in the pathogenesis of NMOSD associated with teratoma.
Third, histopathologic analyses of the teratomas revealed several common features. Although the type of infiltrative lymphocytes in the neural tissue component was variable, $\mathrm{GFAP}^{+}$neural tissue (glial component) with AQP4 immunoreactivity and infiltration of lymphocytes were consistent in all 5 cases. Most of the teratomas (96\%) from patients with anti-NMDAR encephalitis (the most common form of PND) contained a neural tissue component compared with $38 \%$ of sporadic teratomas, and they exhibited higher lymphocyte infiltration frequency into the neural tissue. ${ }^{9}$ These findings suggest that teratomas featuring AQP $4^{+}$neural tissue accompanied by infiltrating lymphocytes contribute to NMOSD development. In contrast to a previous study, intratumoral complement immunoreactivity was observed in this case. ${ }^{7}$ However, complement immunoreactivity has been observed even in sporadic teratomas $(62.5 \%) .{ }^{10}$ Therefore, further study is needed to elucidate the contribution of the complement system in NMOSD associated with teratoma.

Another common feature is the negative conversion of AQP4IgG after tumor removal, which was evident in 3 of 5 cases. Although AQP4-IgG was found in the present case at the last follow-up, the titer kept decreasing after tumor removal (8.7 $\mathrm{U} / \mathrm{mL}$, assessed by ELISA). The conversion may also be due to the effect of the immunotherapies; however, our finding also suggests that paraneoplastic autoimmunity is involved in NMOSD associated with teratoma.

Finally, in this article, 3 of 6 (50\%) patients who developed NMOSD were younger than 30 years. Although the age at 

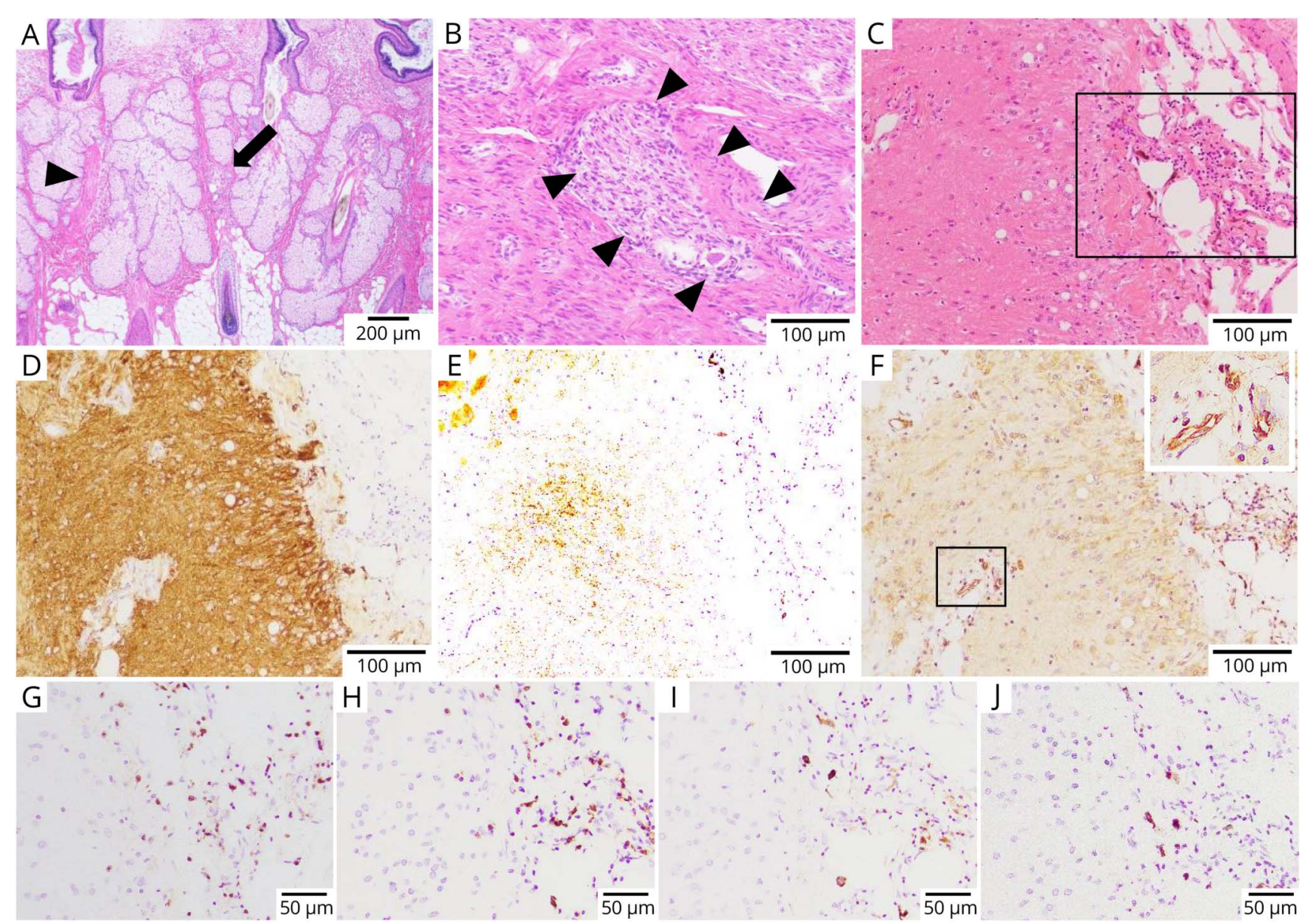

(A and B) Sweat glands (arrow), arrector pili muscles (arrowhead), adipose tissues, and sebaceous glands (A), and peripheral nerve bundles (arrowheads) (B) are observed in the ovarian teratoma (hematoxylin and eosin [HE]). Panels (C-J) are consecutive sections stained with HE (C) and immunostained for GFAP (D), AQP4 (E), C9neo (F), CD45RO (G), CD8 (H), CD20 (I), and CD138 (J). (C) The tumor tissue specimen contains CNS-like tissue with inflammatory cell infiltration (HE). The CNS-like tissue is composed of astrocytic fibrils positive for GFAP (D) and AQP4 (E), and shows C9neo-positive deposits, particularly in the wall of capillary vessels at a higher magnification (F). Inset in (F) is a higher magnification image of the square area outlined in the panel. The infiltrating inflammatory cells are T cells positive for CD45RO (G) or CD8 (H). Only a few CD20-positive B cells (I) and CD138-positive plasma cells (J) are observed. Panels (G-J) are higher magnification images of the square area outlined in panel C. AQP4 = aquaporin-4.

onset of nonparaneoplastic NMOSD is typically around $35-45$ years, ${ }^{3}$ similar to that of NMOSD associated with teratoma, the younger onset cases may reflect the tumorigenesis of teratoma. The median onset age of paraneoplastic NMOSD (associated with other cancers) was greater (55 years) than that of non-paraneoplastic NMOSD (40 years), which can be attributed to the age at tumor onset in paraneoplastic NMOSD. ${ }^{2}$ Therefore, we hypothesize that the age at onset of NMOSD associated with teratoma also correlates with the age at onset of teratoma.

A previous study on autoimmune GFAP astrocytopathy, a newly recognized CNS disease with CSF GFAP $\alpha$-IgG positivity, showed that multiple tumors were found in $22 \%$ of patients diagnosed with this disease. ${ }^{11}$ Although GFAP $\alpha$-IgG was negative in the present case, several common characteristics between NMOSD associated with teratoma and autoimmune GFAP astrocytopathy were observed. Among tumors that are found in cases of autoimmune GFAP astrocytopathy, ovarian teratoma is the most common (approximately $60 \%$ of tumors). In addition, ovarian teratoma from a patient with autoimmune GFAP astrocytopathy demonstrated GFAP staining. ${ }^{12}$ Moreover, autoimmune GFAP astrocytopathy showed high OCB positivity (54\%). Of interest, in addition to GFAP $\alpha-\operatorname{IgG}$, coexistence of AQP4-IgG and/or anti-NMDAR antibody was observed in more than half of the autoimmune GFAP astrocytopathy patients with teratomas (serologic complexity). ${ }^{11}$ These findings suggest common pathogenesis of teratoma-associated CNS autoimmune diseases.

This study suggests that ovarian teratoma may trigger paraneoplastic NMOSD. Therefore, it is crucial to screen even young patients with NMOSD for tumors, particularly teratomas. 
Table Comparison of the Present Case and Previously Reported Cases

\begin{tabular}{|c|c|c|c|c|c|c|}
\hline & $\begin{array}{l}\text { 1: Present } \\
\text { case }\end{array}$ & $\begin{array}{l}\text { 2: Frasquet } \\
\text { et al. } .^{5}\end{array}$ & $\begin{array}{l}\text { 3: Zoccarato } \\
\text { et al. }{ }^{6} \cdot a\end{array}$ & $\begin{array}{l}\text { 4: Bernard-Valnet } \\
\text { et al. }{ }^{7} \# 1\end{array}$ & $\begin{array}{l}\text { 5: Bernard-Valet } \\
\text { et al. }{ }^{7} \# 2\end{array}$ & $\begin{array}{l}\text { 6: Bernard-Valnet } \\
\text { et al. } .^{7} \# 3\end{array}$ \\
\hline Age at clinical onset/sex & $27 / F$ & $42 / F$ & $50 / F$ & $15 / F$ & $21 / F$ & $48 / \mathrm{F}$ \\
\hline Follow-up period, mo & 16 & 12 & 27 & 25 & 24 & 24 \\
\hline Myelitis/optic neuritis/brainstem lesion & $+/-/+$ & $+/-/+$ & $+/+/+$ & $+/-/+$ & $+/+/+$ & $+/-/-$ \\
\hline Nausea and/or vomiting & + & + & - & + & + & + \\
\hline CSF pleocytosis/OCB & $-/+$ & $+/+$ & $-1-$ & $+/+$ & $+/+$ & $+/+$ \\
\hline Dorsal brainstem lesion in MRI & + & + & + & + & + & - \\
\hline \multicolumn{7}{|l|}{ Teratoma pathologyb } \\
\hline Neural tissue & + & + & NA & + & + & + \\
\hline Astrocytic gliosis & + & + & NA & + & + & + \\
\hline AQP4 immunoreactivity & + & + & NA & + & + & + \\
\hline Complement deposition & + & NA & NA & - & - & - \\
\hline Lymphocytic infiltration & + & + & NA & + & + & + \\
\hline Relapse after removal of teratoma & - & - & + & - & - & - \\
\hline $\begin{array}{l}\text { Negative conversion of AQP4-IgG after } \\
\text { removal of teratoma }\end{array}$ & - & NA & - & + & + & + \\
\hline \multicolumn{7}{|c|}{$\begin{array}{l}\text { Abbreviations: AQP4 = aquaporin-4; IgG = immunoglobulin G; NA = not available; NMOSD = neuromyelitis optica spectrum disorder; OCB = oligoclonal IgG } \\
\text { band. } \\
\text { Detailed pathologic findings were available for } 4 \text { of } 5 \text { previously reported cases. } .^{5,7} \text { Histopathologic analysis of the teratoma revealed a mature cystic teratoma } \\
\text { in all } 4 \text { previously reported cases. } \\
\text { a This case developed NMOSD after the onset of anti-NMDAR encephalitis ( } 5 \text { mo after teratoma removal). }{ }^{6} \\
{ }^{b} \text { Removal of teratoma was performed in all } 5 \text { previously reported cases. } .^{5-7}\end{array}$} \\
\hline
\end{tabular}

\section{Acknowledgment}

The authors thank Dr. Toshiyuki Takahashi (Department of Neurology, Tohoku University, Japan) for analyzing the AQP4-IgG and MOG-IgG, Dr. Akio Kimura (Department of Neurology, Gifu University Graduate School of Medicine, Japan) for analyzing the GFAP $\alpha-\operatorname{IgG}$, and Mizuho Karita for excellent technical assistance.

\section{Study Funding}

This work was supported in part by the Health and Labour Sciences Research Grant on Intractable Diseases (Neuroimmunological Diseases) from the Ministry of Health, Labour and Welfare of Japan (20FC1030).

\section{Disclosure}

A. Shimomura, M. Suzuki, K. Shimoji, T. Motohashi, T. Yamamoto, N. Shibata, and K. Kitagawa report no disclosures relevant to the manuscript. R. Ikeguchi received honoraria for talks from Alexion Pharmaceuticals, Chugai Pharmaceutical Co, Ltd, and Novartis Pharma. Y. Shimizu received honoraria for talks from Alexion Pharmaceuticals, Bayer Yakuhin, and Chugai Pharmaceutical Co, Ltd; and personal compensation for consulting services from Biogen Idec Japan, Teijin Pharma, and Novartis Pharma. Go to Neurology.org/NN for full disclosures.

\section{Publication History}

Received by Neurology: Neuroimmunology \& Neuroinflammation March 15, 2021. Accepted in final form May 24, 2021.

Appendix Authors

\begin{tabular}{lll}
\hline Name & Location & Contribution \\
\hline $\begin{array}{l}\text { Ryotaro } \\
\text { Ikeguchi, MD, } \\
\text { PhD }\end{array}$ & $\begin{array}{l}\text { Tokyo Women's Medical } \\
\text { University, Tokyo, Japan }\end{array}$ & $\begin{array}{l}\text { Design and conceptualized } \\
\text { the study; analyzed the } \\
\text { data; and drafted the } \\
\text { manuscript for intellectual } \\
\text { content }\end{array}$ \\
\hline $\begin{array}{l}\text { Yuko Shimizu, } \\
\text { MD, PhD }\end{array}$ & $\begin{array}{l}\text { Tokyo Women's Medical } \\
\text { University, Tokyo, Japan }\end{array}$ & $\begin{array}{l}\text { Design and conceptualized } \\
\text { the study; analyzed the } \\
\text { data; and drafted the } \\
\text { manuscript for intellectual } \\
\text { content }\end{array}$ \\
$\begin{array}{l}\text { Ayato } \\
\text { Shimomura, } \\
\text { MD }\end{array}$ & $\begin{array}{l}\text { Tokyo Women's Medical } \\
\text { University, Tokyo, Japan }\end{array}$ & $\begin{array}{l}\text { Analyzed the data } \\
\text { and critically reviewed the } \\
\text { manuscript }\end{array}$ \\
\hline $\begin{array}{l}\text { Miki Suzuki, } \\
\text { MD, PhD }\end{array}$ & $\begin{array}{l}\text { Tokyo Women's Medical } \\
\text { University, Tokyo, Japan }\end{array}$ & $\begin{array}{l}\text { Analyzed the data and } \\
\text { critically reviewed the } \\
\text { manuscript }\end{array}$ \\
\hline $\begin{array}{l}\text { Kanoko } \\
\text { Shimoji, MD }\end{array}$ & $\begin{array}{l}\text { Tokyo Women's Medical } \\
\text { University, Tokyo, Japan }\end{array}$ & \begin{tabular}{l} 
Analyzed the data \\
\hline
\end{tabular}
\end{tabular}


Appendix (continued)

\begin{tabular}{lll}
\hline Name & Location & Contribution \\
\hline $\begin{array}{l}\text { Takashi } \\
\text { Motohashi, } \\
\text { MD }\end{array}$ & $\begin{array}{l}\text { Tokyo Women's Medical } \\
\text { University, Tokyo, Japan }\end{array}$ & Analyzed the data \\
\hline $\begin{array}{l}\text { Tomoko } \\
\text { Yamamoto, } \\
\text { MD, PhD }\end{array}$ & $\begin{array}{l}\text { Tokyo Women's Medical } \\
\text { University, Tokyo, Japan }\end{array}$ & $\begin{array}{l}\text { Analyzed the data and drafted } \\
\text { the manuscript }\end{array}$ \\
$\begin{array}{l}\text { Noriyuki } \\
\text { Shibata, MD, } \\
\text { PhD }\end{array}$ & $\begin{array}{l}\text { Tokyo Women's Medical } \\
\text { University, Tokyo, Japan }\end{array}$ & $\begin{array}{l}\text { Analyzed the data and drafted } \\
\text { the manuscript }\end{array}$ \\
\hline $\begin{array}{l}\text { Kazuo } \\
\text { Kitagawa, MD, } \\
\text { PhD }\end{array}$ & $\begin{array}{l}\text { Tokyo Women's Medical } \\
\text { University, Tokyo, Japan }\end{array}$ & $\begin{array}{l}\text { Drafted the manuscript and } \\
\text { critically reviewed the } \\
\text { manuscript }\end{array}$ \\
& &
\end{tabular}

\section{References}

1. Dalmau J, Rosenfeld MR. Paraneoplastic syndromes of the CNS. Lancet Neurol. 2008; $7(4): 327-340$.

2. Sepúlveda M, Sola-Valls N, Escudero D, et al. Clinical profile of patients with paraneoplastic neuromyelitis optica spectrum disorder and aquaporin-4 antibodies. Mult Scler J. 2018;24(13):1753-1759.
3. Zekeridou A, Lennon VA. Aquaporin-4 autoimmunity. Neurol Neuroimmunol Neuroinflamm. 2015;2(4):e110.

4. Sudo A, Chihara N, Takenaka Y, et al. Paraneoplastic NMOSD associated with EG junction adenocarcinoma expressing unprotected AQP4. Neurol Neuroimmunol Neuroinflamm. 2018;5(5):e482.

5. Frasquet $\mathrm{M}$, Bataller L, Torres-Vega E, et al. Longitudinally extensive transverse myelitis with AQP4 antibodies revealing ovarian teratoma. J Neuroimmunol. 2013, 263(1-2):145-147

6. Zoccarato M, Saddi MV, Serra G, et al. Aquaporin-4 antibody neuromyelitis optica following anti-NMDA receptor encephalitis. J Neurol. 2013;260(12): 3185-3187.

7. Bernard-Valnet R, Cobo-Calvo A, Siegfried A, et al. Paraneoplastic neuromyelitis optica and ovarian teratoma: a case series. Mult Scler Relat Disord. 2019;31: 97-100.

8. Takahashi T, Miyazawa I, Misu T, et al. Intractable hiccup and nausea in neuromyelitis optica with anti-aquaporin-4 antibody: a herald of acute exacerbations. J Neurol Neurosurg Psychiatry. 2008;79(9):1075-1078.

9. Chefdeville A, Treilleux I, Mayeur ME, et al. Immunopathological characterization of ovarian teratomas associated with anti-N-methyl-D-aspartate receptor encephalitis. Acta Neuropathol Commun. 2019;7(1):38.

10. Martinez-Hernandez E, Horvath J, Shiloh-Malawsky Y, Sangha N, Martinez-Lage M, Dalmau J. Analysis of complement and plasma cells in the brain of patients with anti-NMDAR encephalitis. Neurology. 2011;77(6):589-593.

11. Flanagan EP, Hinson SR, Lennon VA, et al. Glial fibrillary acidic protein immunoglobulin $\mathrm{G}$ as biomarker of autoimmune astrocytopathy: analysis of 102 patients. Ann Neurol. 2017;81(2):298-309.

12. Dubey D, Hinson SR, Jolliffe EA, et al. Autoimmune GFAP astrocytopathy: prospective evaluation of 90 patients in 1 year. J Neuroimmunol. 2018;321: 157-163. 


\section{Neurology \\ Neuroimmunology \& Neuroinflammation}

\section{Paraneoplastic AQP4-IgG-Seropositive Neuromyelitis Optica Spectrum Disorder Associated With Teratoma: A Case Report and Literature Review \\ Ryotaro Ikeguchi, Yuko Shimizu, Ayato Shimomura, et al. \\ Neurol Neuroimmunol Neuroinflamm 2021;8; \\ DOI 10.1212/NXI.0000000000001045}

This information is current as of July 20, 2021

Updated Information \&

Services

References

Subspecialty Collections

Permissions \& Licensing

Reprints including high resolution figures, can be found at:

http://nn.neurology.org/content/8/5/e1045.full.html

This article cites 12 articles, 3 of which you can access for free at: http://nn.neurology.org/content/8/5/e1045.full.html\#\#ref-list-1

This article, along with others on similar topics, appears in the following collection(s):

Paraneoplastic syndrome

http://nn.neurology.org//cgi/collection/paraneoplastic_syndrome

Information about reproducing this article in parts (figures,tables) or in its entirety can be found online at:

http://nn.neurology.org/misc/about.xhtml\#permissions

Information about ordering reprints can be found online: http://nn.neurology.org/misc/addir.xhtml\#reprintsus

Neurol Neuroimmunol Neuroinflamm is an official journal of the American Academy of Neurology.

Published since April 2014, it is an open-access, online-only, continuous publication journal. Copyright

Copyright $(\subseteq 2021$ The Author(s). Published by Wolters Kluwer Health, Inc. on behalf of the American

Academy of Neurology.. All rights reserved. Online ISSN: 2332-7812.

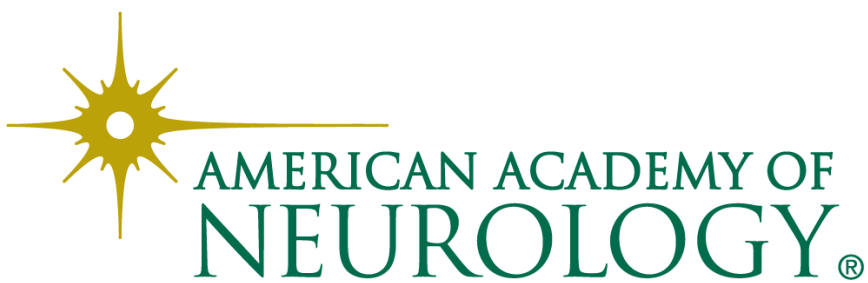

